\title{
Immune-Enhancing Effects of Crude Polysaccharides from Korean Ginseng Berries on Spleens of Mice with Cyclophosphamide- Induced Immunosuppression
}

\author{
Ju Hyun Nam ${ }^{1 \dagger}$, JeongUn Choi ${ }^{1 \dagger}$, Chaiwat Monmai ${ }^{2}$, Weerawan Rod-in ${ }^{2}$, A-yeong Jang ${ }^{1}$, \\ SangGuan You ${ }^{1,2}$, and Woo Jung Park ${ }^{1,2 *}$
}

${ }^{1}$ Department of Wellness-Bio Industry, Gangneung-Wonju National University, Gangneung 25457, Republic of Korea ${ }^{2}$ Department of Marine Food Science and Technology, Gangneung-Wonju National University, Gangneung 25457, Republic of Korea

\begin{abstract}
Panax ginseng C. A. Meyer is well known as traditional herbal medicine, and ginseng berries are known to exhibit potential immune-enhancing functions. However, little is known about the in vivo immunomodulatory activity of Korean ginseng berries. In this study, crude Korean ginseng berries polysaccharides (GBP) were isolated and their immunomodulatory activities were investigated using cyclophosphamide (CY)-induced immunosuppressive BALB/c mice. In CY-treated mice, oral administration of GBP (50-500 mg/kg BW) remarkably increased their spleen sizes and spleen indices and activated NK cell activities. GBP also resulted in the proliferation of splenic lymphocytes (coordinating with ConA: plant mitogen which is known to stimulate T-cell or LPS: endotoxin which binds receptor complex in B cells to promote the secretion of pro-inflammatory cytokines) in a dosedependent manner. In addition, GBP significantly stimulated mRNA expression levels of immuneassociated genes including interleukin-1 $\beta$ (IL-1 $\beta$ ), IL-2, IL-4, IL-6, tumor necrosis factor- $\alpha$ (TNF- $\alpha$ ), interferon- $\gamma$ (IFN- $\gamma$ ), toll-like receptor 4 (TLR-4), and cyclooxygenase-2 (COX-2) in CY-treated mice. These results indicate that GBP is involved in immune effects against $\mathrm{CY}$-induced immunosuppression. Thus, GBP could be developed as an immunomodulation agent for medicinal or functional food application.
\end{abstract}

Keywords: Korean ginseng berry, polysaccharides, cyclophosphamide, immune-enhancing effect

Received: October 15, 2021 Accepted:December 15, 2021

First published online: December 17, 2021

*Corresponding author Phone: $+82-33-640-2857$ Fax: $+82-33-640-2850$ E-mail: pwj0505@gwnu.ac.kr

${ }^{\dagger}$ These authors contributed equally to this study.

pISSN 1017-7825 elSSN 1738-8872

Copyright $\odot 2022$ by the authors. Licensee KMB. This article is an open access article distributed under the terms and conditions of the Creative Commons Attribution (CC BY) license.

\section{Introduction}

The immune system is an organization of cells and molecules that defends the body against infection. It consists of two main subsystems: the innate immune system and the adaptive immune system [1]. Immune responses such as immune organ indices (bone marrow, spleen, thymus) and changes in the population of immune cells (macrophage, splenocytes, neutrophils, natural killer cells) are essential mechanisms for enhancing the body's immune function [2]. These responses activate a variety of immunomodulating functions by producing various cytokines (such as interferon- $\gamma$ (IFN- $\gamma$ ), tumor necrosis factor- $\alpha$ (TNF- $\alpha$ ), interleukin-2 (IL-2), and IL-6) and other inflammatory mediators $[3,4]$. Natural products from plant extracts have the ability to stimulate the host immune system and can serve as potential therapies to substitute for chemotherapy [5-7].

Anti-cancer drugs such as cyclophosphamide (CY) have been used in chemotherapy to treat cancer, autoimmune diseases, and immune-mediated diseases. However, they can produce serious side effects such as cytotoxicity and oxidative stress [8]. In addition, they can damage the DNAs of normal cells and lead to a significant immunosuppressive condition [5,9]. In such case, it is important to recover the immunosuppressive condition [8]. The CY-induced immunosuppressive mice model has been used in many previous studies to assess the immunomodulatory effects of functional materials [10-12].

Polysaccharides are a class of bioactive macromolecular substances with beneficial pharmacological activities that include anti-tumor, antioxidant, anti-diabetic, and immunomodulatory effects [13-15]. Polysaccharides extracted from plants such as Lonicera japonica, Codonopsis pilosula, Sargassum fusiforme, Panax quinquefolius L., and Lycium ruthenicum have been reported to exert immunomodulatory effects in CY-induced mice $[5,12,16$ 18]. Panax ginseng C. A. Meyer is one of the most commonly used traditional medicinal plants in Korea, China, and some other East Asian countries [19]. Ginseng berry has been reported to exhibit immune-modulating, anticancer, anti-aging, and anti-diabetic effects [20-24]. Polysaccharides are major bioactive constituents isolated 
from $P$. ginseng $[25,26]$. It has been reported that polysaccharides of $P$. ginseng can exert immunomodulatory activities in both in vitro and in vivo systems [27-29]. Crude polysaccharides from $P$. quinquefolius can increase macrophage phagocytosis and nitric oxide (NO) production as well as splenic lymphocyte proliferation [17]. Polysaccharides from Korean ginseng after cellulase- and $\alpha$-amylase-based extraction can enhance spleen and thymus indices, lymphocyte proliferation, leukocyte count, NK cell activity, and serum levels of IL-2, IL-6, and IFN- $\gamma$ in CY-induced immunosuppressed mice [30]. Moreover, we recently reported that Korean ginseng berries show immune-enhancing effects in RAW 264.7 cells [31]. However, still little is known about the immunomodulatory effect of polysaccharides from Korean ginseng berry in CY-induced immunosuppressive mice model. Therefore, our objective in the current study was to investigate the in vivo immune-enhancing properties of crude Korean ginseng berry polysaccharides (GBP).

\section{Materials and Methods}

Animals

Six-week-old male BALB/c mice (21-23 g) were obtained from the Central Lab, Animal Inc. (Korea). Animals were housed under standard conditions with temperature maintained at $22 \pm 2^{\circ} \mathrm{C}$ and a 12 -h/12-h dark/light cycle for at least one week before the experiments. A standard laboratory diet and water were provided to all mice. All experimental processes were approved by the Gangneung-Wonju National University Committee.

\section{Korean Ginseng Berry Polysaccharides}

Korean ginseng berries were obtained from Boeun, Chungcheong Province, Korea. Korean GBPs with molecular weights of 328.4 and $54.2 \times 10^{3}(\mathrm{~g} / \mathrm{mol})$ comprising rhamnose $(4.0 \%)$, arabinose $(19.8 \%)$, mannose (2.2\%), glucose $(27.7 \%)$, and galactose $(46.3 \%)$ were prepared as described in our previous report [31].

\section{Immunosuppressive Treatments}

In this study, 40 mice were randomly divided into 8 groups ( $n=5$ per group) for various treatments (Table 1 ). CY was used to induce immunosuppressive models by intraperitoneal (IP) injection at a dose of $80 \mathrm{mg} / \mathrm{kg}$ body weight (BW). Levamisole (LEV) and commercial red ginseng syrup were used as positive controls at doses of 40 $\mathrm{mg} / \mathrm{kg} \mathrm{BW}$ and $100 \mathrm{mg} / \mathrm{kg} \mathrm{BW}$, respectively. LEV is an immunomodulatory agent that can modulate cellmediated, i.e., T cell-directed immunity $[3,32]$. Ginseng is a commercially available product that can modulate the immune system [33]. Mice were sacrificed at $24 \mathrm{~h}$ after the last treatment.

\section{Measurement of Spleen Index}

The spleen was dissected and weighed. The spleen index was calculated according to the formula as follows:

Spleen index $(\mathrm{mg} / \mathrm{g})=$ the spleen weight/the body weight of mouse.

\section{Preparation of Mouse Splenocytes}

Splenocytes were isolated from spleens of $\mathrm{BALB} / \mathrm{c}$ mice. After weighing, spleens of mice were placed in ice-cold PBS for splenocyte isolation. These splenocytes were extracted using RBC Lysis Buffer (eBioscience, USA) according to the manufacturer's instructions. Cells were adjusted to a concentration of $2 \times 10^{6}$ cells $/ \mathrm{ml}$ in RPMI1640 medium (Gibco Laboratories, USA) supplemented with $1 \%$ fetal bovine serum and $1 \%$ streptomycin $(100 \mu \mathrm{g} / \mathrm{ml})$ penicillin $(100 \mathrm{IU} / \mathrm{ml})$ (Welgene, Korea).

\section{Measurement of Splenocyte Proliferation}

EZ-Cytox Cell Viability Assay Kit (Daeillab Service, Korea) was used to evaluate splenic lymphocyte proliferation. Splenocytes were seeded into a 96 -well plate and cultured at $37^{\circ} \mathrm{C}$ with $5 \% \mathrm{CO}_{2}$ for $1 \mathrm{~h}$. These cells were then stimulated with $5 \mu \mathrm{g} / \mathrm{ml}$ concanavalin A (Con A) as T cell mitogen or $10 \mu \mathrm{g} / \mathrm{ml}$ lipopolysaccharide (LPS) as B cell mitogen. After incubation at $37^{\circ} \mathrm{C}$ with $5 \% \mathrm{CO}_{2}$ for $48 \mathrm{~h}, 25 \mu \mathrm{l} \mathrm{EZ-Cytox} \mathrm{reagent} \mathrm{was} \mathrm{added} \mathrm{to} \mathrm{each} \mathrm{well}$ and plates were incubated at $37^{\circ} \mathrm{C}$ with $5 \% \mathrm{CO}_{2}$ for another $1 \mathrm{~h}$. The absorbance at $450 \mathrm{~nm}$ was then measured using a microplate reader (EL800; BioTek, USA).

\section{Analysis of NK Cell-Mediated Cytotoxicity Assay}

Splenocytes were co-cultured with or without YAC-1 cells (Korean Cell Line Bank) to obtain a 50:1 ratio of

Table 1. BALB/c mouse groups with different treatments.

\begin{tabular}{llcl}
\hline \multirow{2}{*}{ Group } & & Treatment & \\
\cline { 2 - 4 } & Day 1 to 6 (orally) & Day 4 to 6 (IP) & Day 7 to 10 (orally) \\
\hline Normal & Saline & - & Saline \\
Red ginseng & Saline & CY & Saline \\
LEV & Ginseng syrup & CY & Ginseng syrup \\
Tr. 1 & Levamisole & CY & Levamisole \\
Tr. 2 & GBP $(50 \mathrm{mg} / \mathrm{kg} \mathrm{BW})$ & CY & GBP $(50 \mathrm{mg} / \mathrm{kg} \mathrm{BW})$ \\
Tr. 3 & GBP $(100 \mathrm{mg} / \mathrm{kg} \mathrm{BW})$ & CY & GBP $(100 \mathrm{mg} / \mathrm{kg} \mathrm{BW})$ \\
Tr. 4 & GBP $(250 \mathrm{mg} / \mathrm{kg} \mathrm{BW})$ & CY & GBP $(250 \mathrm{mg} / \mathrm{kg} \mathrm{BW})$ \\
& GBP $(500 \mathrm{mg} / \mathrm{kg} \mathrm{BW})$ & CY & GBP $(500 \mathrm{mg} / \mathrm{kg} \mathrm{BW})$ \\
\hline
\end{tabular}


Table 2. List of primers used for real-time PCR analysis.

\begin{tabular}{|c|c|c|}
\hline Gene & Accession No. & Primer sequences (5' to 3') \\
\hline IL-1 $\beta$ & NM_008361.4 & $\begin{array}{l}\text { Forward: GGGCCTCAAAGGAAAGAATC } \\
\text { Reverse: TACCAGTTGGGGAACTCTGC }\end{array}$ \\
\hline IL-2 & NM_008366.3 & $\begin{array}{l}\text { Forward: CCTGAGCAGGATGGAGAATTACA } \\
\text { Reverse: TCCAGAACATGCCGCAGAG }\end{array}$ \\
\hline IL-4 & NM_021283.2 & $\begin{array}{l}\text { Forward: ACAGGAGAAGGGACGCCAT } \\
\text { Reverse: GAAGCCCTACAGACGAGCTCA }\end{array}$ \\
\hline IL-6 & NM_031168.2 & $\begin{array}{l}\text { Forward: AGTTGCCTTCTTGGGACTGA } \\
\text { Reverse: CAGAATTGCCATTGCACAAC }\end{array}$ \\
\hline TNF- $\alpha$ & D84199.2 & $\begin{array}{l}\text { Forward: ATGAGCACAGAAAGCATGATC } \\
\text { Reverse: TACAGGCTTGTCACTCGAATT }\end{array}$ \\
\hline IFN- $\gamma$ & NM_008337.3 & $\begin{array}{l}\text { Forward: CTCAAGTGGCATAGATGT } \\
\text { Reverse: GAGATAATCTGGCTCTGCAGGATT }\end{array}$ \\
\hline TLR-4 & NM_021297.3 & $\begin{array}{l}\text { Forward: CGCTCTGGCATCATCTTCAT } \\
\text { Reveres: GTTGCCGTTTCTTGTTCTTCC }\end{array}$ \\
\hline COX-2 & NM_011198.4 & $\begin{array}{l}\text { Forward: AGAAGGAAATGGCTGCAGAA } \\
\text { Reverse: GCTCGGCTTCCAGTATTGAG }\end{array}$ \\
\hline$\beta$-actin & NM_007393.5 & $\begin{array}{l}\text { Forward: CCACAGCTGAGAGGGAAATC } \\
\text { Reverse: AAGGAAGGCTGGAAAAGAGC }\end{array}$ \\
\hline
\end{tabular}

effector cells to NK-sensitive target cells. After $24 \mathrm{~h}$ incubation, the supernatant was collected after centrifugation at $250 \times g$ for $5 \mathrm{~min}$. The activity of NK cells was assessed with a CytoTox 96 Non-Radioactive Cytotoxicity Assay Kit (Promega, USA). The absorbance at $490 \mathrm{~nm}$ was then measured.

\section{Quantitative RT-PCR (qRT-PCR) Analysis}

Tri reagent (Molecular Research Center, Inc., USA) was employed to extract total RNAs from splenic lymphocytes. Total RNAs were then reverse-transcribed to cDNA using a High-Capacity cDNA Reverse Transcription Kit (Applied Biosystems, USA). To amplify the cDNA, the cDNA was subjected to qRT-PCR using TB Green Premix Ex Taq II (Takara Bio Inc., Japan) on a QuantStudio 3 Flex Real-Time PCR System (Thermo Fisher Scientific, USA). Amplification conditions were as follows: initial denaturation at $95^{\circ} \mathrm{C}$ for $30 \mathrm{~s}$, followed by 40 cycles of $95^{\circ} \mathrm{C}$ for $5 \mathrm{~s}$ and $60^{\circ} \mathrm{C}$ for $34 \mathrm{~s}$. Primer sequences are listed in Table 2.

\section{Statistical Analysis}

The significance of differences was evaluated using one-way analysis of variance (ANOVA) followed by Tukey's post-hoc test using Statistix 8.1 Statistics software (Statistix, USA). Significant difference between treatment groups was considered when the $p$-value was less than 0.05 .

\section{Results}

\section{Effect of GBP on Spleen Index in CY-Treated Mice}

The effects of ginseng berry polysaccharides (GBP) on spleen size and spleen indices of BALB/c mice are shown in Fig. 1. Compared with the normal group, the CY-treated group showed significant decreases of both spleen size and spleen index. Compared with the CY group, the LEV treatment group and the red ginseng syrup treatment group showed increased spleen index. GBP groups also showed significantly increased spleen indices in a dosedependent manner $(50,100,250$, and $500 \mathrm{mg} / \mathrm{kg} \mathrm{BW})$.

\section{Effects of GBP on Splenic Lymphocyte Proliferation}

The effects of GBP on mitogen-stimulated spleen lymphocyte proliferation are shown in Fig. 2. The CY group showed significantly reduced Con A- or LPS-stimulated cell proliferation (48.1\% and $57.1 \%$, respectively) compared to the normal group. GBP at doses of 250 and $500 \mathrm{mg} / \mathrm{kg}$ BW significantly stimulated the proliferation of splenocytes induced by Con A or LPS compared to the CY group. The proliferation of lymphocytes of the group treated with GBP at $500 \mathrm{mg} / \mathrm{kg}$ BW was higher than those of positive control groups (red ginseng syrup and LEV).

\section{Effect of GBP on Splenic NK Cell Activity}

As shown in Fig. 3, CY strongly inhibited the activity of NK cells to $42.9 \%$. NK activity of the GBP group at $50 \mathrm{mg} / \mathrm{kg}$ BW showed little difference from that of the CY group. However, the NK cell activities of GBP treatment groups at doses of 100,250 , and $500 \mathrm{mg} / \mathrm{kg} \mathrm{BW}$ were significantly higher than those of the CY group in a dosedependent manner. In addition, GBP at a dose of $500 \mathrm{mg} / \mathrm{kg}$ BW recovered the splenic NK cell activity up to a level similar to that of the normal group.

\section{Effect of GBP on Gene Expression in CY-Treated Mice}

To assess whether GBP could stimulate immune responses in splenic lymphocytes stimulated by T-cell mitogen (Con A) and B-cell mitogen (LPS), real-time PCR was performed to examine mRNA expression levels of immunerelated genes such as $I L-1 \beta, I L-2, I L-4, I L-6, T N F-\alpha, I F N-\gamma, T L R-4$, and COX-2. As shown in Fig. 4, mRNA expression levels of these genes in CY group were lower than those of the normal group. All GBP groups (50-500 $\mathrm{mg} / \mathrm{kg} \mathrm{BW}$ ) showed markedly increased expression levels of immune-related genes than the CY group. GBP 
A

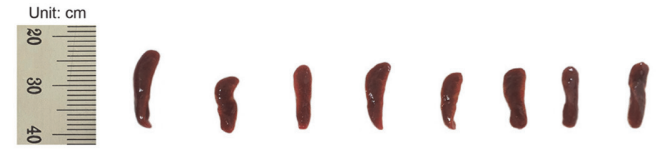

$\mathrm{GBP}$ (mg/kg BW)

$50 \quad 100 \quad 250 \quad 500$

Red Ginseng (mg/kg BW)

Levamisole (mg/kg BW)

CY $(80 \mathrm{mg} / \mathrm{kg} \mathrm{BW})$

B

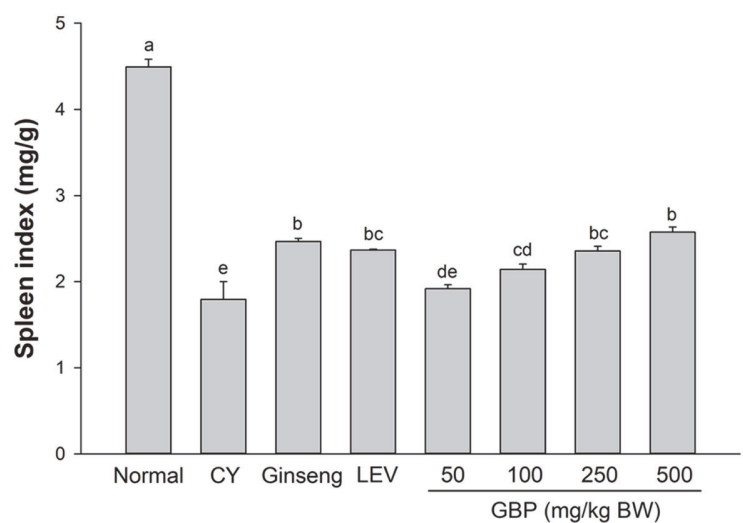

Fig. 1. Effects of GBP at various concentrations on spleen size and spleen index. (A) Effects on spleen size, (B) Effects on spleen index. Results are expressed as means \pm SD. Different letters $(a-e)$ indicate significant $(p<0.05)$ differences between treatment groups.

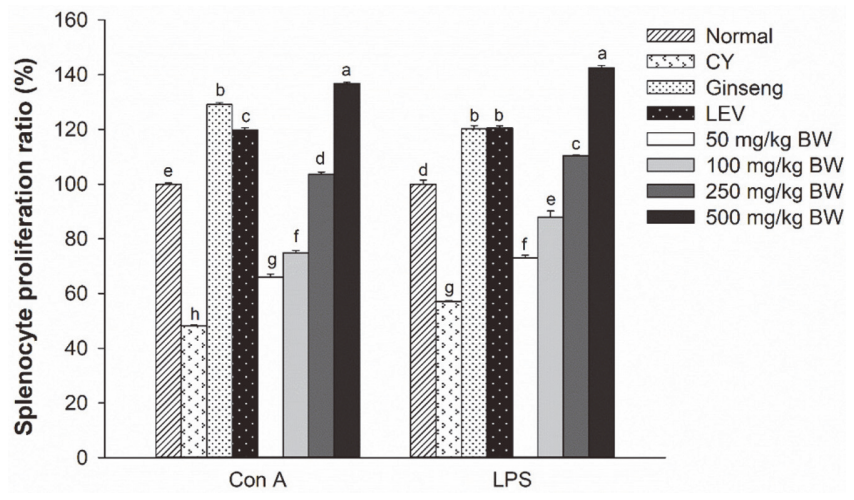

Fig. 2. Effects of GBP on Con A- and LPS-induced splenocyte proliferation. Results are expressed as means \pm SD. Different letters $(\mathrm{a}-\mathrm{h})$ indicate significant $(p<0.05)$ differences between treatment groups.

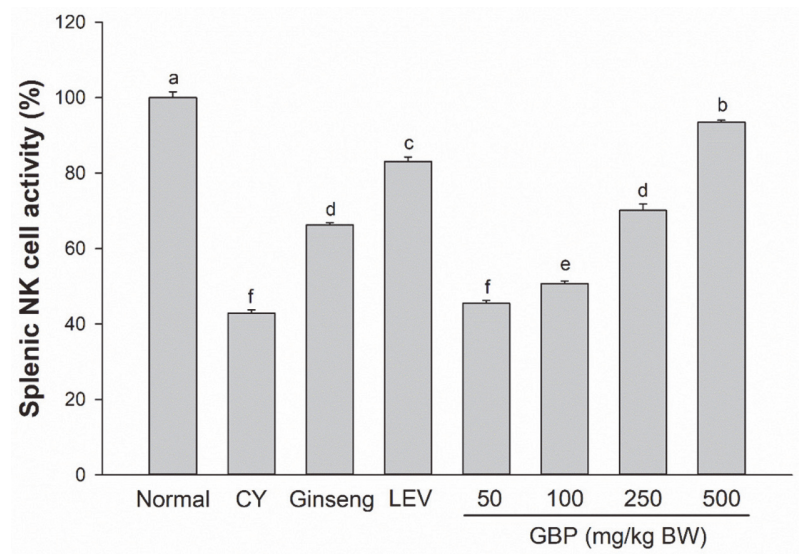

Fig. 3. Effects of GBP on splenic NK cell activity. Results are expressed as means \pm SD. Different letters (a-f) indicate significant $(p<0.05)$ differences between treatment groups. 
A
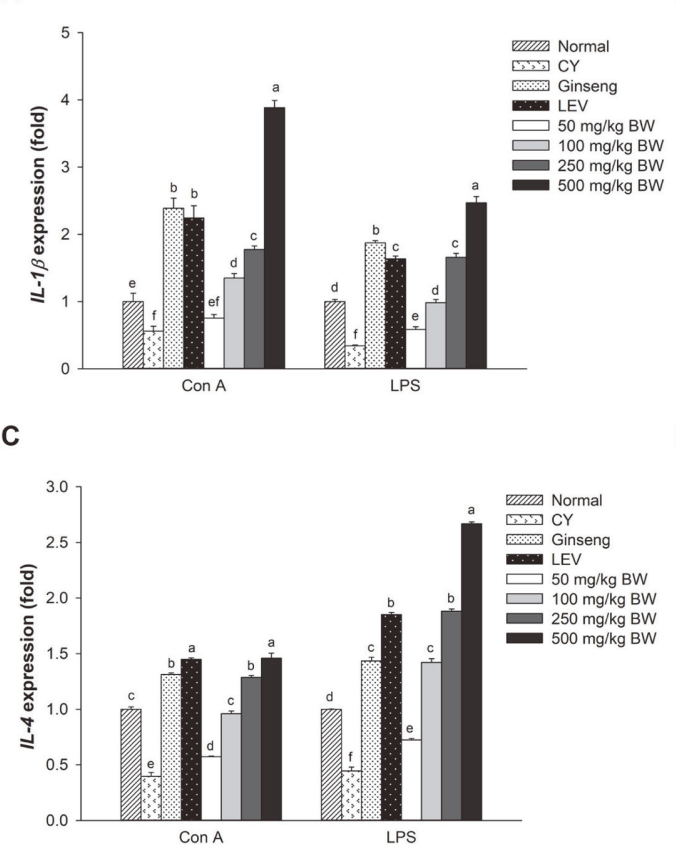

E
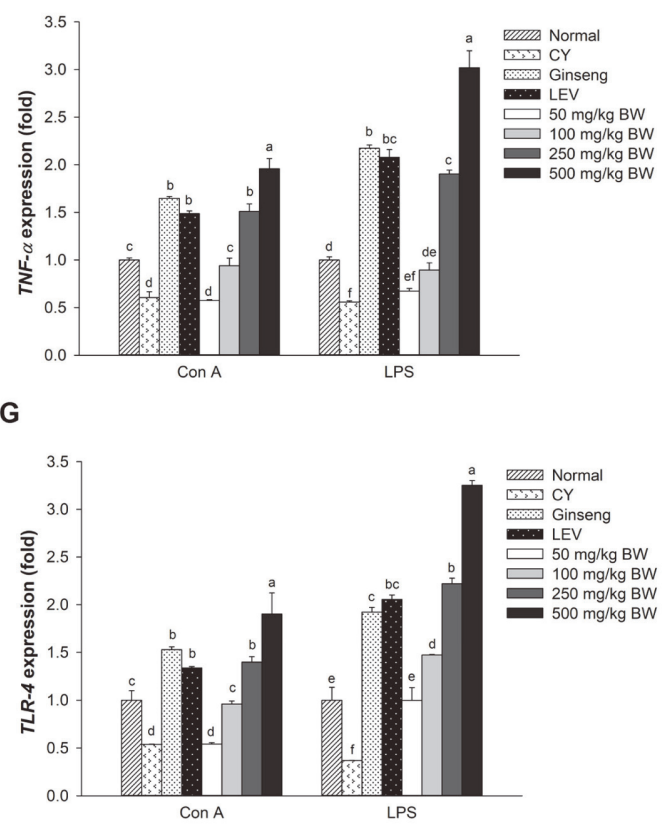

B

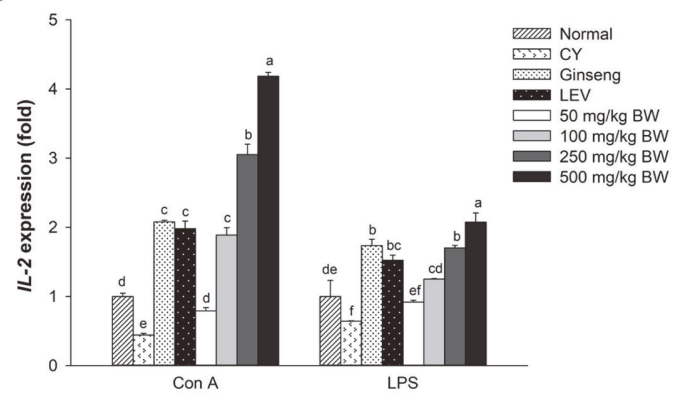

D

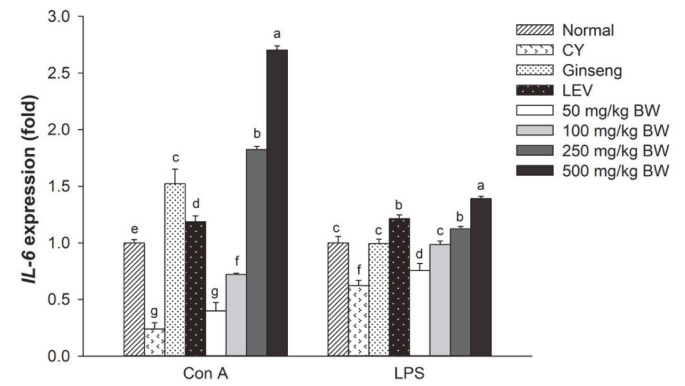

$\mathbf{F}$

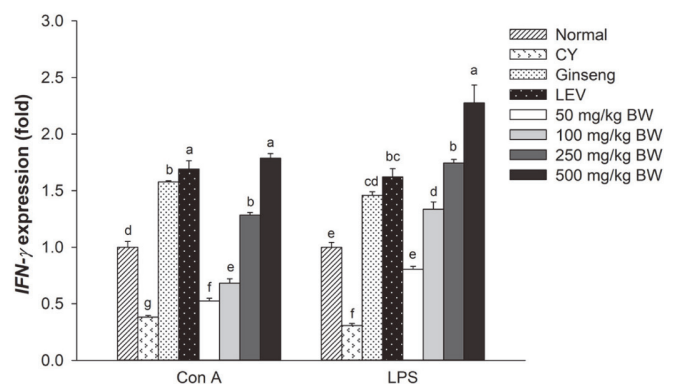

H

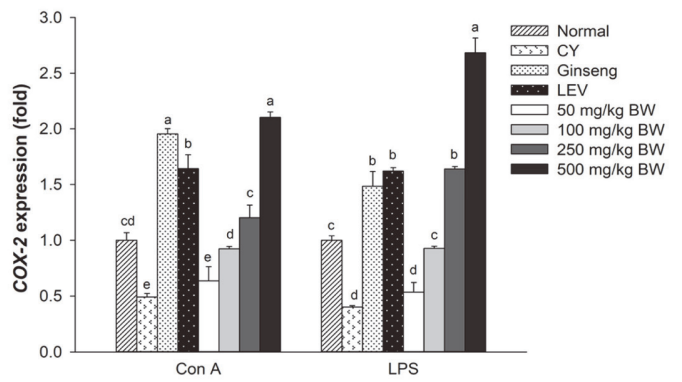

Fig. 4. Effects of GBP on mRNA expression levels of immune-related genes in mitogen-stimulated splenic lymphocytes. (A) $I L-1 \beta$, (B) $I L-2$, (C) $I L-4$, (D) $I L-6$, (E) TNF- $\alpha$, (F) $I F N-\gamma$, (G) TLR-4, and (H) COX-2 expression. Results are displayed as means \pm SD. Different letters $(\mathrm{a}-\mathrm{g})$ indicate significant $(p<0.05)$ differences between treatment groups.

treatment groups, expression levels of $I L-1 \beta, I L-2$, and $I L-6$ were significantly upregulated by T-cell mitogens than by B-cell mitogens (Figs. 4A, 4B, and 4D). Conversely, IL-4, TNF- $\alpha, I F N-\gamma, T L R-4$, and COX-2 expression levels were significantly upregulated by B-cell mitogens than by T-cell mitogens (Figs. 4C, 4E-4H). At the highest doses (250 and $500 \mathrm{mg} / \mathrm{kg} \mathrm{BW),} \mathrm{GBP}$ also increased expression levels of these genes than the normal group.

\section{Discussion}

In this study, we investigated the potential of Korean GBPs to activate immune systems in a CY-induced immunosuppressed mice model. Modulation of splenic lymphocytes was determined by cell proliferation, NK cell activity, and immune-associated gene expression. CY is an inducer of immunosuppression. It is a widely used alkylating agent for cancer therapy [8]. In mice models, the effect of CY could be shown as reduction of immune 
organ index. The capacity of the immune system decreases after CY treatment $[5,12]$. In addition, immunestimulating agents such as LEV and red ginseng syrup were applied as positive controls to recover the immunosuppressive condition induced by CY.

The spleen is one of the most critical immune organs. It plays an important role in the body's immune function by regulating immune responses. Their weights and organ indices indicate the function of innate immunity to some extent $[10,34]$. In this study, spleen indices of mice treated with LEV, red ginseng syrup, and GBP were higher than that of the CY group. Treatments with GBP $(50-500 \mathrm{mg} / \mathrm{kg} \mathrm{BW})$ remarkably increased spleen weights of CY-treated mice, indicating that GBP could regulate immune organs to improve immune damage caused by CY (Fig. 1). Similar to our study results, Song et al. have reported that polysaccharides extracted from Korean ginseng with enzyme-assisted extraction can increase spleen and thymus indices, enhance the proliferation of lymphocytes and NK cell activity, and increase serum levels of IL-2, IL-6, and IFN- $\gamma$ in CY-induced BALB/c mice [30].

Lymphocytes are major cellular components of the adaptive immune response. They can be divided mainly into $\mathrm{T}$ cells and $\mathrm{B}$ cells depending on their developmental site, surface, antigen, receptor, and function [3]. They are involved in activating the processes of antigen presentation and mitogen stimulation [35]. Splenic lymphocyte proliferation is an important biomarker for the activation of cellular and humoral immune responses [36]. This activity is induced by mitogen Con A or LPS, which is commonly used to evaluate T or B lymphocyte activity [34]. In the present study, proliferation assay results showed that GBP could significantly promote Con A- and LPSstimulated splenocyte proliferation and restore its decrease induced by CY (Fig. 2). Especially, high doses of GBP $(250-500 \mathrm{mg} / \mathrm{kg} \mathrm{BW})$ showed strong immune-enhancing effects on mitogen-induced proliferation. Similar to our results, American ginseng polysaccharides can also promote the proliferation of $\mathrm{B}$ cells or $\mathrm{T}$ cells in these dose ranges [17].

Wang et al. [24] have reported that ginseng fruit polysaccharides can inhibit tumor growth and lung metastasis, promote spleen lymphocyte proliferation, increase NK cell activities, and increase serum concentrations of IL- 2 and IFN- $\gamma$ in a Lewis lung carcinoma (LLC)-bearing mouse model. Our results showed that NK cell activity was attenuated by CY administration, whereas GBP treatment significantly enhanced the activity of NK cells from splenocytes, similar to positive controls (red ginseng syrup and LEV).

After activation, splenic lymphocytes can secrete several cytokines, chemokines, and other inflammatory mediators to regulate functions of other innate and adaptive immune cells $[16,37]$. Cytokines play an important role in immune responses by modulating immune-related cells (B cells, T cells, and NK cells) and non-immune cells (endothelial cells, epidermal cells, and fibroblasts) [3,9]. Helper T cells (Th cells) are essential immunoregulatory cells of the body [38]. Th 1 cells can produce type 1 cytokines (IL-2, TNF- $\alpha$, IFN- $\gamma$ ), while Th 2 cells can produce type 2 cytokines (IL-4, IL-5, IL-6, IL-10, IL-13) [39]. Many studies have shown that plantderived polysaccharides can modulate the secretion of cytokines $[4,12,16]$. The present results showed that GPB treatment increased expression levels of cytokines (IL-1 $\beta, I L-2, I L-4, I L-6, T N F-\alpha$, and $I F N-\gamma)$ in a dose-dependent manner and that high doses (250 and $500 \mathrm{mg} / \mathrm{kg} \mathrm{BW}$ ) of GBP could improve these cytokines more so than the normal control (Fig. 4). GBP treatment also upregulated TLR-4 and COX-2 expression depending on its concentration (Fig. 4). COX-2 is an inflammatory mediator. COX-2-mediated $\mathrm{PGE}_{2}$ plays an important role in IFN- $\gamma$ and IL-12 production of BALB/c spleen cells [40]. TLR-4 has a fundamental role in the initiation of adaptive immunity, activation of cells, and pathogen recognition. It can also induce the expression of TNF- $\alpha, I L-$ $1 \beta$, and $I L-6[4]$. These results suggest that GBP could improve immune activity by upregulating the expression of cytokines induced by CY.

Korean GBPs exhibited potent immunomodulatory properties in a CY-induced immunosuppressed mice model. GBP treatment enhanced immune responses by improving the spleen index. It markedly restored splenocyte proliferation and NK cell activity. It also upregulated gene expression of immune-regulated cytokines. This is the first study to report that GBP possesses immune-enhancing activity in an in vivo mice model, suggesting that GBP could be developed as an effective immunomodulatory agent.

\section{Acknowledgments}

This study was partially supported by a grant (No. 2019R1A2B5B01070542) from the Basic Science Research Program of the National Research Foundation (NRF) funded by the Ministry of Science, ICT \& Future Planning, Republic of Korea. This research was also supported by a grant (No. 2018R1A61A03023584) from the University Emphasis Research Institute Support Program funded by the NRF, Republic of Korea.

\section{Conflict of Interest}

The authors have no financial conflicts of interest to declare.

\section{References}

1. Delves PJ, Roitt IM. 2000. The immune system. N. Engl. J. Med. 343: 37-49.

2. Zhang WN, Gong LL, Liu Y, Zhou ZB, Wan CX, Xu JJ, et al. 2020. Immunoenhancement effect of crude polysaccharides of Helvella leucopus on cyclophosphamide-induced immunosuppressive mice. J. Funct. Foods 69: 103942.

3. Huang L, Shen M, Wu T, Yu Y, Yu Q, Chen Y, et al. 2020. Mesona chinensis Benth polysaccharides protect against oxidative stress and immunosuppression in cyclophosphamide-treated mice via MAPKs signal transduction pathways. Int. J. Biol. Macromol. 152: 766-774.

4. Guo MZ, Meng M, Feng CC, Wang X, Wang CL. 2019. A novel polysaccharide obtained from Craterellus cornucopioides enhances immunomodulatory activity in immunosuppressive mice models via regulation of the TLR4-NF- $\mathrm{B}$ pathway. Food Funct. 10: 4792-4801. 
5. Bai RB, Zhang YJ, Fan JM, Jia XS, Li D, Wang YP, et al. 2020. Immune-enhancement effects of oligosaccharides from Codonopsis pilosula on cyclophosphamide induced immunosuppression in mice. Food Funct. 11: 3306-3315.

6. Sak, K. 2012. Chemotherapy and dietary phytochemical agents. Chemother. Res. Pract. 2012: 282570

7. Shirani K, Hassani FV, Razavi-Azarkhiavi K, Heidari S, Zanjani BR, Karimi G. 2015. Phytotrapy of cyclophosphamide-induced immunosuppression. Environ. Toxicol. Pharmacol. 39: 1262-1275.

8. Ahlmann M., Hempel G. 2016. The effect of cyclophosphamide on the immune system: implications for clinical cancer therapy. Cancer Chemother. Pharmacol. 78: 661-671.

9. Zhou Y, Chen X, Yi R, Li G, Sun P, Qian Y, et al. 2018. Immunomodulatory effect of tremella polysaccharides against cyclophosphamide-induced immunosuppression in mice. Molecules 23: 239

10. Hao LX, Zhao XH. 2016. Immunomodulatory potentials of the water-soluble yam (Dioscorea opposita Thunb) polysaccharides for the normal and cyclophosphamide-suppressed mice. Food Agric. Immunol. 27: 667-677.

11. Zhou R, He D, Xie J, Zhou Q, Zeng H, Li H, Huang L. 2021. The synergistic effects of polysaccharides and ginsenosides from American ginseng (Panax quinquefolius L.) ameliorating cyclophosphamide-induced intestinal immune disorders and gut barrier dysfunctions based on microbiome-metabolomics analysis. Front. Immunol. 12: 1273.

12. Zhou X, Dong Q, Kan X, Peng L, Xu X, Fang Y, et al. 2018. Immunomodulatory activity of a novel polysaccharide from Lonicera japonica in immunosuppressed mice induced by cyclophosphamide. PLoS One 13: e0204152.

13. Kouakou K, Schepetkin IA, Yapi A, Kirpotina LN, Jutila MA, Quinn MT. 2013. Immunomodulatory activity of polysaccharides isolated from Alchornea cordifolia. J. Ethnopharmacol. 146: 232-242.

14. Wang X, Gao A, Jiao Y, Zhao Y, Yang X. 2018. Antitumor effect and molecular mechanism of antioxidant polysaccharides from Salvia miltiorrhiza Bunge in human colorectal carcinoma LoVo cells. Int. J. Biol. Macromol. 108: 625-634.

15. Xie JT, Wu JA, Mehendale S, Aung HH, Yuan CS. 2004. Anti-hyperglycemic effect of the polysaccharides fraction from American ginseng berry extract in ob/ob mice. Phytomedicine 11: 182-187.

16. Chen X, Nie W, Fan S, Zhang J, Wang Y, Lu J, Jin L. 2012. A polysaccharide from Sargassum fusiforme protects against immunosuppression in cyclophosphamide-treated mice. Carbohydr. Polym. 90: 1114-1119.

17. Yu XH, Liu Y, Wu XL, Liu LZ, Fu W, Song DD. 2017. Isolation, purification, characterization and immunostimulatory activity of polysaccharides derived from American ginseng. Carbohydr. Polym. 156: 9-18.

18. Gong Y, Wu J, Li S-T. 2015. Immuno-enhancement effects of Lycium ruthenicum Murr. polysaccharide on cyclophosphamideinduced immunosuppression in mice. Int. J. Clin. Exp. Med. 8: 20631-20637.

19. Yoon D, Choi BR, Kim YC, Oh SM, Kim HG, Kim JU, et al. 2019. Comparative analysis of Panax ginseng berries from seven cultivars using UPLC-QTOF/MS and NMR-based metabolic profiling. Biomolecules 9: 424.

20. Folmer F, Basavaraju U, Jaspars M, Hold G, El-Omar E, Dicato M, et al. 2014. Anticancer effects of bioactive berry compounds. Phytochem. Rev. 13: 295-322.

21. Kim J, Cho S, Kim S, Kim S, Park C, Park H, et al. 2016. Ginseng berry, a promising anti-aging strategy: recent opinions on the biological effects of a traditional Korean ingredient. J. Adv. Res. Biotechnol. 1: 8.

22. Park EY, Kim HJ, Kim YK, Park SU, Choi JE, Cha JY, et al. 2012. Increase in insulin secretion induced by Panax ginseng berry extracts contributes to the amelioration of hyperglycemia in streptozotocin-induced diabetic mice. J. Ginseng Res. 36: 153-160.

23. Shao ZH, Xie JT, Vanden Hoek TL, Mehendale S, Aung H, Li CQ, et al. 2004. Antioxidant effects of American ginseng berry extract in cardiomyocytes exposed to acute oxidant stress. Biochim. Biophys. Acta 1670: 165-171.

24. Wang Y, Huang M, Sun R, Pan L. 2015. Extraction, characterization of a Ginseng fruits polysaccharide and its immune modulating activities in rats with Lewis lung carcinoma. Carbohydr. Polym. 127: 215-221.

25. Lee JI, Park KS, Cho IH. 2019. Panax ginseng: a candidate herbal medicine for autoimmune disease. J. Ginseng Res. 43: 342-348.

26. Wang CZ, Anderson S, Du W, He TC, Yuan CS. 2016. Red ginseng and cancer treatment. Chin. J. Nat. Med. 14: 7-16.

27. Lee DY, Park CW, Lee SJ, Park HR, Seo DB, Park JY, et al. 2019. Immunostimulating and antimetastatic effects of polysaccharides purified from ginseng berry. Am. J. Chinese Med. 47: 823-839.

28. Zheng L, Wang M, Peng Y, Li X. 2017. Physicochemical characterization of polysaccharides with macrophage immunomodulatory activities isolated from red ginseng (Panax ginseng C. A. Meyer). J. Chem. 2017: 3276430.

29. Chen LX, Qi YL, Qi Z, Gao K, Gong RZ, Shao ZJ, et al. 2019. A comparative study on the effects of different parts of Panax ginseng on the immune activity of cyclophosphamide-induced immunosuppressed mice. Molecules 24: 1096

30. Song YR, Sung SK, Jang M, Lim TG, Cho CW, Han CJ, et al. 2018. Enzyme-assisted extraction, chemical characteristics, and immunostimulatory activity of polysaccharides from Korean ginseng (Panax ginseng Meyer). Int. J. Biol. Macromol. 116: 1089 -1097.

31. Rod-in W, Talapphet N, Monmai C, Jang Ay, You S, Park WJ. 2021. Immune enhancement effects of Korean ginseng berry polysaccharides on RAW264.7 macrophages through MAPK and NF-kB signalling pathways. Food Agric. Immunol. 32: 298-309.

32. Renoux G. 1980. The general immunopharmacology of levamisole. Drugs 20: 89-99.

33. Riaz M, Rahman NU, Zia-Ul-Haq M, Jaffar HZE, Manea R. 2019. Ginseng: A dietary supplement as immune-modulator in various diseases. Trends Food Sci. Technol. 83: 12-30.

34. Du XF, Jiang CZ, Wu CF, Won EK, Choung SY. 2008. Synergistic immunostimulating activity of pidotimod and red ginseng acidic polysaccharide against cyclophosphamide-induced immunosuppression. Arch. Pharm. Res. 31: 1153-1159.

35. Yu Q, Nie S-P, Wang J-Q, Huang D-F, Li W-J, Xie M-Y. 2015. Molecular mechanism underlying chemoprotective effects of Ganoderma atrum polysaccharide in cyclophosphamide-induced immunosuppressed mice. J. Funct. Foods. 15: 52-60.

36. Meng Y, Li B, Jin D, Zhan M, Lu J, Huo G. 2018. Immunomodulatory activity of Lactobacillus plantarum KLDS1.0318 in cyclophosphamide-treated mice. Food Nutr. Res. 62. doi: 10.29219/fnr.v62.1296. eCollection 2018.

37. Wang, H., Yang, S., Wang, Y., Jiang, T., Li, S., Lv, Z. 2017. Immunoenhancement effects of glycosaminoglycan from Apostichopus japonicus: In vitro and in cyclophosphamide-induced immunosuppressed mice studies. Mar. Drugs 15: 347.

38. Wen ZS, Tang Z, Gu LX, Xiang XW, Qu YL. 2019. Immunomodulatory effect of low molecular-weight seleno-aminopolysaccharide on immunosuppressive mice. Int. J. Biol. Macromol. 123: 1278-1288.

39. Tsiligianni I, Antoniou KM, Kyriakou D, Tzanakis N, Chrysofakis G, Siafakas NM, et al. 2005. Th1/Th2 cytokine pattern in bronchoalveolar lavage fluid and induced sputum in pulmonary sarcoidosis. BMC Pulm. Med. 5: 8 .

40. Kuroda E, Sugiura T, Zeki K, Yoshida Y, Yamashita U. 2000. Sensitivity difference to the suppressive effect of prostaglandin $E_{2}$ among mouse strains: A possible mechanism to polarize Th2 Type response in BALB/c Mice. J. Immunol. 164: 2386. 